Slot 코팅 공정에서 Non-Newtonian 유체의 코팅 균일성을 위한 최적 다이 설계

\author{
이시형* · 고현정* · 심서훈** · 정현욱** · 현재천* \\ *고려대학교 화공생명공학과 \\ 136-713 서울시 성북구 안암동 5 가 \\ **제일모직 R\&D 연구소 \\ 437-711 경기도 의왕시 고천동 332-3번지 \\ (2010년 10월 29일 접수, 2010년 12월 9일 채택)
}

\title{
An Optimal Die Design for the Coating Uniformity of Non-Newtonian Liquids in Slot Coating Process
}

\author{
Si Hyung Lee*, Hyun Jung Koh*, Seo Hoon Shim**, Hyun Wook Jung*,† and Jae Chun Hyun* \\ *Department of Chemical and Biological Engineering, Korea University, 5-ga, Anam-dong, Seongbuk-gu, Seoul 136-713, Korea \\ **Cheil Industries R\&D Center, 332-3, Gocheon-dong, Uiwang-si, Gyeonggi 437-711, Korea \\ (Received 29 October 2010; accepted 9 December 2010)
}

\begin{abstract}
요 약
본 연구에서는 전산유체모사기인 Fluent를 활용하여 slot 다이 내부에서 Newtonian과 non-Newtonian 코팅액의 동적 거동을 고찰함으로써 최적 다이 설계를 위한 방법론을 구축하고자 하였다. 다이 출구에서 코팅액의 속도분포를 일정 하게 하기 위해 chamber 구조를 변화시킴으로써 최적 하이브리드 다이의 설계가 가능하였다. 특히, non-Newtonian 유 체의 경우, 전단담화 정도와 chamber의 coat-hanger 최적 길이의 상관관계를 도출하였다.
\end{abstract}

\begin{abstract}
In this study, the flow behavior of Newtonian and non-Newtonian coating liquids inside slot die has been scrutinized for the purpose of optimal internal die design in slot coating system from three-dimensional computations by CFD Fluent solver. A hybrid slot die could be optimally designed by changing the chamber or manifold structure to guarantee the uniform velocity distribution of coating liquids at die exit. Especially, for the non-Newtonian coating liquids, the length of coat-hanger for the uniform coating has been properly chosen, according to the degree of their shearthinning properties.
\end{abstract}

Key words: Slot Coating, Internal Die Design, Non-Newtonian Coating Liquid, Uniform Coating, Chamber Structure

\section{1. 서 론}

Slot 코팅은 curtain, slide 코팅 등과 같은 전계량(pre-metered) 코 팅 공정의 하나로 web 속도와 코팅두께를 미리 설정하면 공급되는 코팅액을 물성에 상관없이 물질수지식에 의해 계량할 수 있다는 것 과 높은 정밀도 및 빠른 코팅 생산속도를 장점으로 한다. 이러한 특 성으로 인해 이차전지, 디스플레이 산업에서부터 접착성 필름, 제지, 포장재 등의 일반산업 및 가정용 등에 이르기까지 다양한 분야에 활 용되는 등 핵심 요소 기술로 인식되고 있다.

Fig. 1과 같이 slot 코팅 공정은 feed부를 통해서 들어온 코팅액이 다이 내부 chamber(또는 manifold)와 slit 부분을 통과하여 web에 코 팅되어지는 과정으로 이루어진다. 코팅 액이 관(pipe)을 통해서 slot 다이 내부로 들어올 때 첫 번째로 통과하는 부분이 chamber 부분으

\footnotetext{
${ }^{\dagger}$ To whom correspondence should be addressed.

E-mail: hwjung@grtrkr.korea.ac.kr

†이 논문은 고려대학교 홍석인 교수님의 정년을 기념하여 투고되었습니다.
}

로 코팅액을 폭방향으로 분배시켜주는 역할을 한다. 이후 코팅액이 얇은 slit을 통과하여 다이 lip을 통해 web과 만나며 코팅이 이루어 진다. 균일한 코팅 제품을 만들기 위해서는 Fig. 1에서와 같이 다이 출구에서 코팅액이 균일하게 나오도록 다이 내부 구조를 최적화하는 내부설계와 upstream/downstream 다이 lips와 web 사이에 형성되는 코팅 bead 영역을 제어하는 외부설계 기술을 정립해야 한다. 본 연 구에서는 다이 출구에서 유체가 폭방향으로 균일한 속도분포를 갖게 하기 위한 내부 최적설계를 중점적으로 고찰하고자 한다.

Slot 코팅에 대한 연구를 살펴보면, Ruschak[1]이 간단한 모델로부 터 공정의 안정성을 예측하는 이론적인 분석을 처음으로 수행하였다. Higgins와 Scriven[2]은 점성(viscous) 효과와 모세관력(capillary force) 에 대한 부분을 보완하여 Ruschak의 이론을 확장하였고, 일차원(1-D) viscocapillary 모델을 개발하였다. 이러한 1-D viscocapillary 모델은 web 속도와 bead pressure(upstream과 downstream 기상 영역의 압력 차)로 나타내어지는 기본적인 코팅 window를 제시할 수 있었으나, Capillary수 와 Reynolds수가 매우 작은 영역에서만 유효한 제한점을 


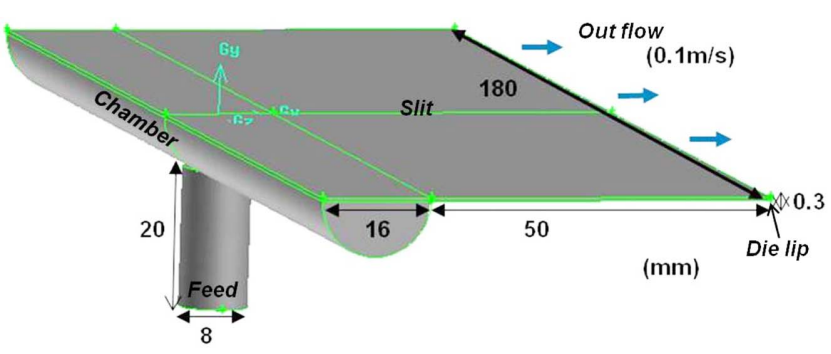

Fig. 1. Internal structure of slot die.

지닌다. 그 이후 Scriven 교수 그룹은 폭방향의 대칭성을 고려해 이 차원(2-D) Navier-Stokes 식에 Galerkin/finite-element method(FEM) 를 활용하여 처음으로 다차원 코팅 유동을 해석하였다[3,4]. Lee 등 [5]의 연구자는 Ruschak[1]과 Higgins/Scriven[2]의 1-D 모델을 실험 결과와 직접 비교 분석하여 코팅 두께가 코팅 속도와 물질의 유변물 성에 큰 영향을 받는다고 보고하였고, 임계 Capillary수를 찾아내면서 1-D 모델의 한계를 밝혔다. Carvalho와 Khesigi[6]는 Capillary수와 Reynolds수가 큰 영역을 포함한 2-D 모델을 실험과 함께 성공적으 로 비교함으로써 실제 공정에 바로 적용가능한 low-flow limit의 개 념을 발표하였다. Ning 등[7], Yang과 Liu[8], Romero와 Carvalho[9] 등은 코팅액의 점탄성적 특성이 slot 코팅 공정에 미치는 영향을 분 석하였다. 코팅 유동을 직접 가시화할 수 있는 기술은 Sartor[3] 및 Ning 등[7]에 의해 더욱 발전되었다.

Slot 다이의 내부 설계를 위해 코팅액의 점도 영향이 반영된 모델을 이용하여 유동 분포를 해석한 여러 연구 그룹이 있다. Carley[10]는 power-law 유체와 비교하여 Newtonian 유체를 사용할 경우 chamber 내부 유동이 더 효율적임을 간단한 식으로 설명하였고, feed 위치에 따 른 유동 비교로부터 다이 설계의 중요성을 강조하였으며, Pearson [11]는 chamber 구조에 대한 폭방향 slit 내부 유동의 균일성 여부를 체계적으로 분석하였다. McKelvey와 Ito[12]와 Matsubara[13]는 일 차원 식을 사용하여 여러 형태의 다이 모양에 대한 유동 특성을 제 시하였고, Lee와 Liu[14]는 단순한 일차원 식으로는 해석이 어려운 non-circular chamber에 대한 이차원 유동 특성을 고찰하였다. Tadmor 등 [15]은 뉴튼성 용액과 비뉴튼성 용액에 대해서 이차원 모 델에 의한 다이 내부 유동을 해석하였고, Wang[16]은 FEM를 이용 하여 coat-hanger 유형의 chamber에 대한 유동 특성을 규명하였으 며, Sartor[3]는 다이 내부 설계를 위한 구조 제어에 관해 정리하 였다.

본 연구에서는 앞서 기술한 바와 같이 공정 변수에 따른 속도분포 의 민감도 분석을 수행하여 비뉴튼성 유체의 균일 코팅을 위한 다이 내부 설계를 최적화하는 것이고, 유변물성과 다이 구조의 상관관계 를 도출하는 것이다. 즉, 뉴튼성 용액과 비뉴튼성 용액에 대한 다이 내부 유동은 전산유체모사 프로그램인 Fluent[17]의 삼차원 모델로 해석하였고, 코팅 불균일성에 영향을 끼치는 주요 인자를 확인하였 다. 또한, 최적 다이 설계를 위한 coat-hanger 형태와 converging 형 태가 결합된 hybrid chamber를 제시하였다. 이를 바탕으로 주요 유 변물성이 변화함에 따라 균일 코팅을 위한 다이 내부 구조 제어법을 확립하고자 하였다. 이와 같은 연구는 새로운 기능성을 부여하기 위 해 동일한 제품군에서 유변물성이 바뀌는 경우, 해당 코팅을 효율적 으로 하기 위한 기본적인 정보를 제공하는데 중요한 역할을 담당할 것으로 사료된다.

\section{Slot 다이 내부 유동 모사}

다이 내부에서의 삼차원 유동을 모사하기 위해서 전산유체역학 (CFD) 프로그램인 Fluent를 활용하였다. 비압축성 유체에 대한 연속 식과 운동식은 아래와 같다.

Continuity equation: $\underline{\nabla} \cdot \underline{u}=0$

Equation of motion: $\rho \frac{\mathrm{Du}}{\mathrm{Dt}}=-\underline{\nabla} \mathrm{P}-\underline{\nabla} \cdot \tau+\rho \mathrm{g}$

$$
\underline{\underline{\tau}}=-\eta(\dot{\gamma}) \underline{\underline{\gamma}}, \eta=\eta_{\infty}+\left(\eta_{o}-\eta_{\infty}\right)\left[1+(\dot{\gamma} \lambda)^{2}\right]^{(n-1) / 2}
$$

여기서 $\underline{u}$ 는 속도, $P$ 는 압력, $\rho$ 는 유체 밀도, $\underline{\underline{\tau}}$ 는 stress, $g$ 는 중력 가속도, $\eta$ 는 Carreau 유체 점도, $\eta_{0}$ 는 zero-shear-rate 점도, $\eta_{\infty}$ 는 무 한점도, $\dot{\gamma}$ 는 변형률속도(strain rate), $\lambda$ 는 전담담화거동이 시작되는 변형률속도의 역수, 그리고 $n$ 은 power-law index를 나타낸다. 경계 조건으로는 feed 입구 부분에서 정해진 유량을, 다이 출구 부분에서 출구 압력을 각각 설정하였다.

Fluent는 연속식과 운동식을 control-volume 기반의 FVM(Finite Volume Method) 기법[17]을 적용하여 계산한다. 즉, 삼차원 계산영 역을 수만개의 미소부피로 세분화하여 각각의 영역에서 지배방정식 으로부터 implicit하게 해를 얻는 방식을 사용한다.

Fig. 1에 slot 다이 내부 구조와 해당 수치가 나타나 있고, 입구에 서의 유량 조건은 다이 출구에서의 평균 속도가 $0.1 \mathrm{~m} / \mathrm{s}$ 이 될 수 있 도록 설정하였다. 계산된 해의 정확도 및 수렴성을 살피기 위해 계 산영역내 mesh수에 따른 다이 출구에서 코팅액의 속도분포 변화를 조사하여 최적의 mesh수를 Fig. 2에서와 같이 도출하였다. 계산시간 을 고려하고 해의 오차를 효율적으로 줄일 수 있도록 육면체 모양의 mesh수를 95,060개로 정하였다. 각 mesh의 길이는 $1 \mathrm{~mm}$ 가 넘지 않 으며 특히, 좁은 slit gap에서는 $0.1 \mathrm{~mm}$ 의 조밀한 mesh를 사용하 였다.

\section{3. 결과 및 고찰}

\section{3-1. 다이 내부 유동 분석}

Slot 다이 내부에서 코팅액의 유동을 분석하고 최적화된 다이를 설 계하고자 하는 이유는 최종 코팅 제품의 균일성을 위해 다이 출구에 서 코팅액의 속도 분포를 균일하게 하기 위함이다. 최적의 다이 내 부 설계를 위해 코팅액의 물성에 따른 유동 해석과 다이 구조에 대

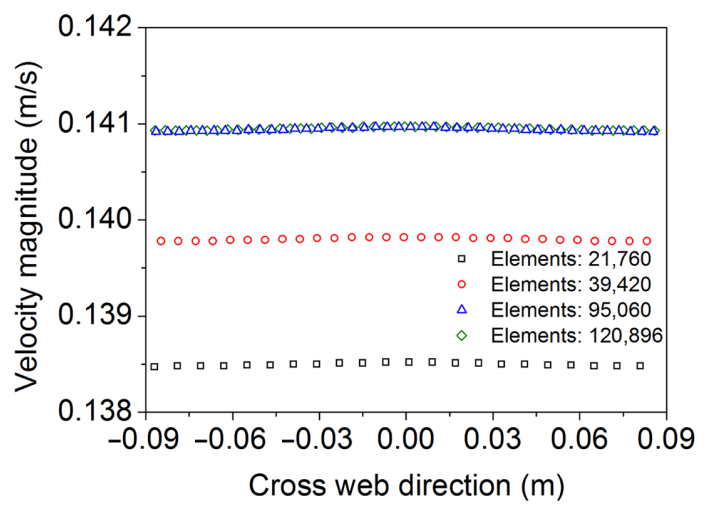

Fig. 2. Effect of mesh size on velocity profiles at die exit for Newtonian liquid.

Korean Chem. Eng. Res., Vol. 49, No. 3, June, 2011 


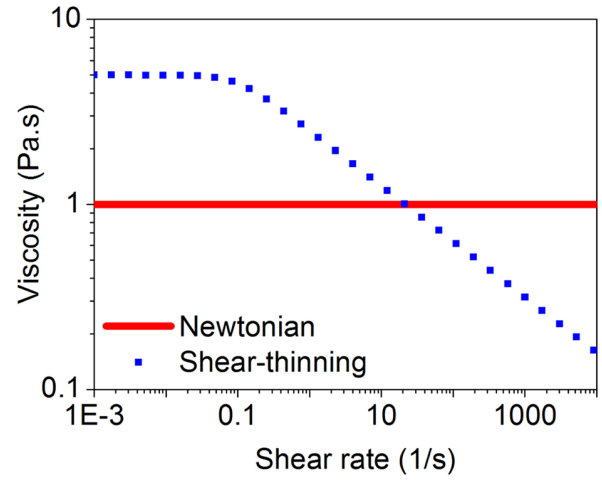

Fig. 3. Shear viscosity curves for both Newtonian and non-Newtonian (shear-thinning) liquids (Carreau model parameters: $\lambda=10, h_{\infty}$ $\left.=0, h_{o}=5, n=0.7, \rho=1,230 \mathrm{~kg} / \mathrm{m}^{3}\right)$.

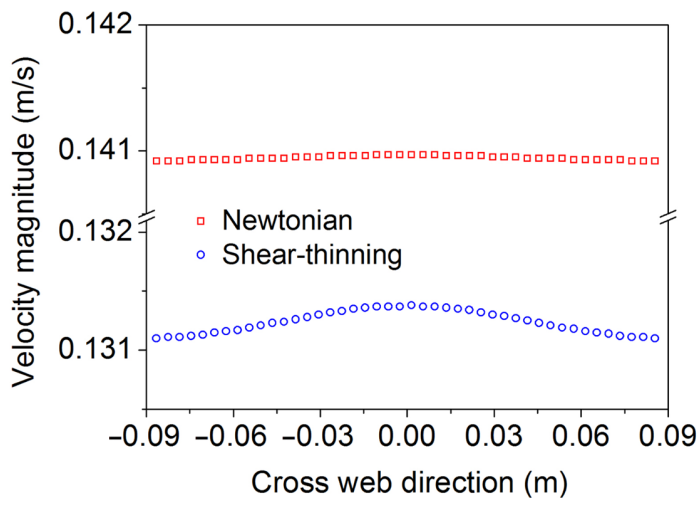

Fig. 4. Velocity profiles along with width direction at die exit for Newtonian and non-Newtonian liquids.

한 영향을 분석하였다. 적용대상 코팅액으로는 뉴튼성 유체와 비뉴 튼성(점단담화; shear-thinning) 유체를 사용하였다. 실제 코팅 산업 에서는 기능성을 갖는 고분자나 여러 종류의 입자를 첨가한 슬러리 나 현탁액을 사용하게 되는데, 이를 고려하기 위해 이차전지 코팅 공 정에서 주로 쓰이는 슬러리의 유변물성을 활용하였다(Fig. 3). 비뉴튼 성 유체의 거동을 고찰하기 위해서 변형률속도에 의존하는 Carreau 점도모델을 채택하였다(Eq. (2.3)). Carreau 모델에서 가장 중요한 인 자라 할 수 있는 power-law index $(n)$ 는 비뉴튼성 유체의 점도가 변 형률속도에 따라 얼마나 민감하게 변화되는지를 나타내준다.

Fig. 4는 다이 출구에서 뉴튼성 유체와 비뉴튼성 유체의 속도분포 차이를 나타낸 결과이다. $x$ 축은 slit 폭방향으로의 좌표를 나타내며, $\mathrm{y}$ 축은 slit 중앙면에서 유체의 출구 속도를 나타낸다. Slit 출구에서의 속도 분포는 최종 코팅 두께와 직결되므로, 다이 내부 구조의 설계 에 있어서 가장 중요한 정보를 제공해준다. 결과에서 보듯이 뉴튼성 유체는 출구에서 폭방향으로 균일한 속도 분포를 유지하는 반면, 비 뉴튼성 유체는 중앙 부분의 속도가 더 빠르고 양단으로 갈수록 감소 하는 분포를 나타낸다. 이러한 불균일한 속도 분포는 최종 코팅 두 께의 불균일성에 그대로 반영되므로 전단담화인 비뉴튼성 유체가 균 일 속도 분포를 갖도록 다이 내부를 변경해야 함은 자명하다.

Figs. 5 와 6 에서와 같이 slit wall 부분에서의 전단변형률속도(shear rate)를 살펴보면, 코팅액의 전단담화 물성이 다이 출구 속도분포에 미치는 영향이 큼을 확인할 수 있다. 뉴튼성 유체의 경우, 전단변형 률속도가 흐름방향의 여러 위치에서 폭방향으로 일정한 반면, 비뉴 튼성 유체의 경우, 폭방향 및 흐름방향으로 변화된 전단변형률속도

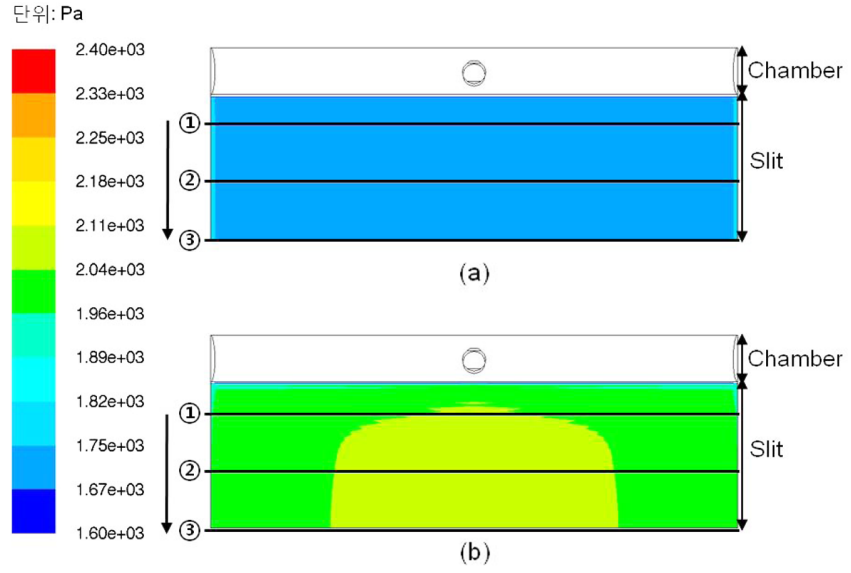

Fig. 5. Wall shear-rate contours of (a) Newtonian and (b) non-Newtonian liquids in slit regime: (1) $10 \mathrm{~mm}$, (2) $30 \mathrm{~mm}$, and (3) $50 \mathrm{~mm}$ from the chamber.
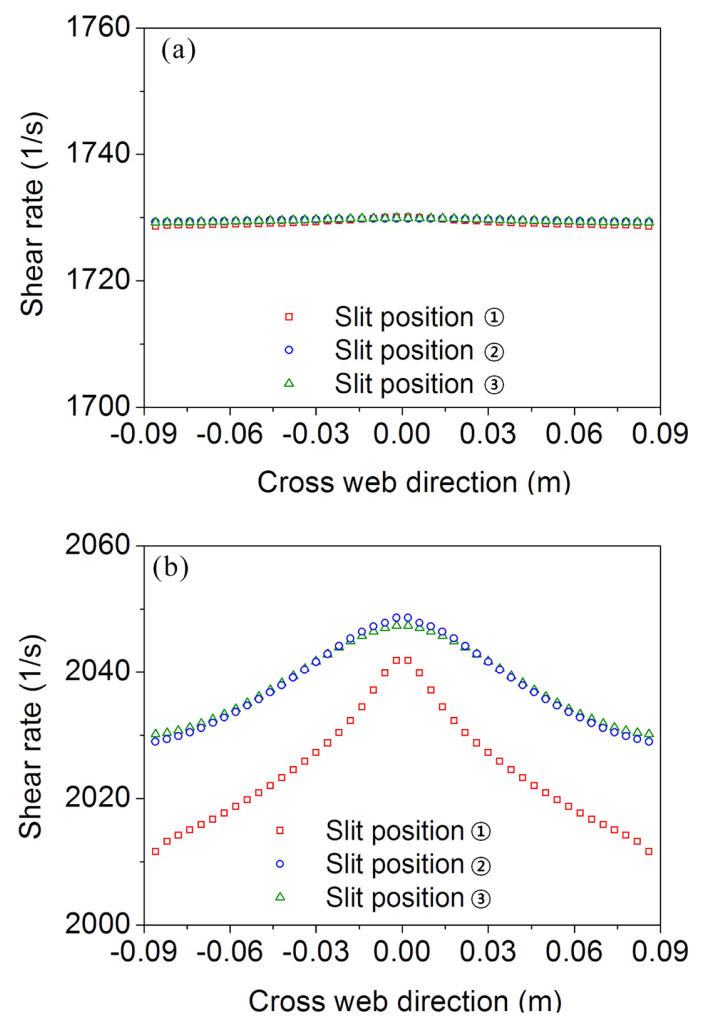

Fig. 6. Wall shear-rate profiles along with width direction for (a) Newtonian and (b) non-Newtonian liquids: (1) $10 \mathrm{~mm}$, (2) $30 \mathrm{~mm}$, and (3) $50 \mathrm{~mm}$ from the chamber.

가 폭방향 점도 변화를 야기하게 되므로 속도분포가 균일하지 않게 된다. 즉, slit 폭 중앙 부분에서의 전단변형률속도가 양단에서의 것 과 비교해서 크다면, 전단담화 특성으로 인해 중앙부분에서 받게 되 는 stress 및 유체 점도가 양단에서의 것보다 상대적으로 감소하여 중 앙 부분에서의 출구 속도가 증가함을 의미한다.

\section{3-2. 공정변수 영향 및 최적 다이 설계}

전단담화 유체에서의 속도 불균일성을 더 고찰해보기 위해 물성 인자를 변화시켜가며 속도 분포의 민감도를 분석하였다. Fig. 7은 power-law index $(n)$ 에 따른 폭방향 속도 분포 변화를 보여준다. 결과 


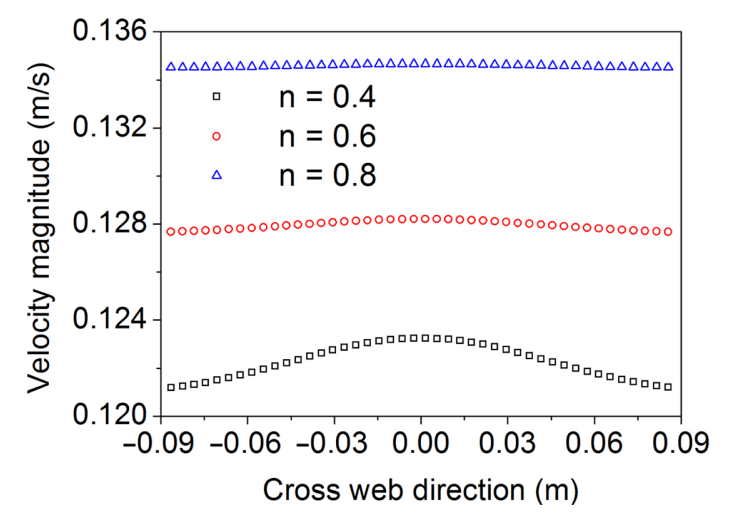

Fig. 7. Effect of power-law index(n) on velocity distribution at die exit for non-Newtonian liquid.

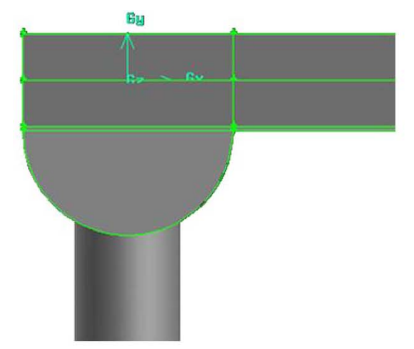

(a)

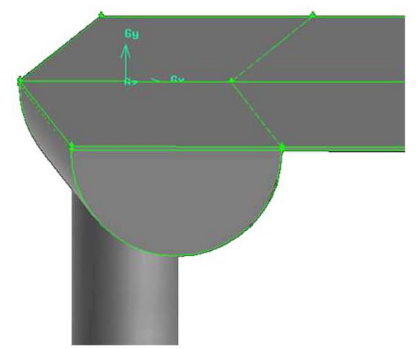

(b)

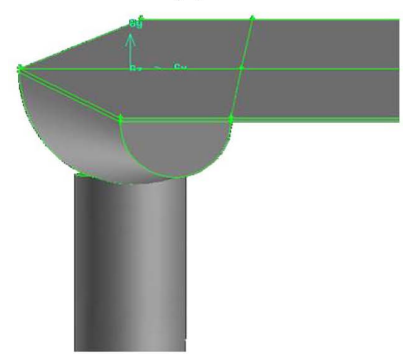

(c)

Fig. 8. Various shapes of chamber or manifold: (a) standard semicircular, (b) coat-hanger, and (c) converging types.

를 제시하지 않았으나 Carreau 모델 내 다른 물성 변수는 $n$ 과 비교 하여 속도분포에 큰 영향을 주지 않았다. 유체의 전담담화 거동이 커 질수록(n이 작아질수록) slit 내부 폭방향으로 전단변형률속도 차이 를 크게 함으로써 속도 불균일성이 증가함을 확인할 수 있다.

전단담화 유체에서 발생하는 코팅 불균일성을 효율적으로 줄여 최 종 코팅 두께의 균일성을 보장할 수 있는 다이 내부 설계를 위해 chamber 구조가 converging한 형태와 coat-hanger 형태를 도입하였 다. 각 다이 개요는 Fig. 8에 나타나 있다. Coat-hanger(Fig. 8(b)) 형 태는 slit의 중앙에 집중되어진 운동량으로 인한 속도 불균일성을 해

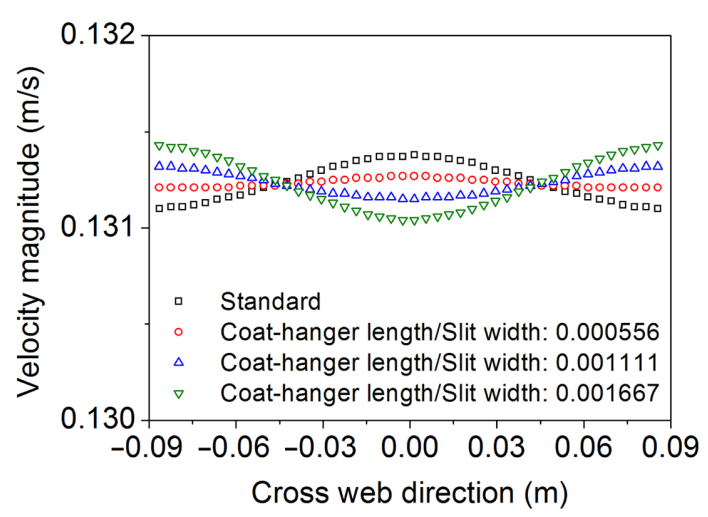

Fig. 9. Effect of coat-hanger length on velocity distribution at die exit for non-Newtonian liquid.

소시키기 위한 구조의 하나로 chamber의 양단을 출구방향으로 당겨 줌으로써 다이 양단에서의 유체 체류시간을 줄여주는데 효과가 있다. Fig. 9는 coat-hanger 정도에 따른 비뉴튼성 유체의 출구 속도분포 변 화를 보여준다. 기본 다이 형태에서의 속도분포와 비교해 본 결과, $0.1 \mathrm{~mm}$ 를 앞당겨준 coat-hanger 구조에서의 출구 속도 분포가 상당 히 균일해졌음을 알 수 있고(Coat-hanger/slit length=0.000556), 이보 다 더 앞당긴 coat-hanger 구조에서는 양단에서의 유체 체류시간이 짧아져 속도분포가 역전되었다.

Converging 다이 형태는(Fig. 8(c)), chamber의 단면이 양단으로 갈 수록 줄어드는 형태이다. 양단에서는 공간적인 이유로 유체가 정체 되어 있는 영역이 필연적으로 존재하므로, 가능하면 양단에서의 chamber 영역을 줄이는 것이 실제적이다. 특히, 입자를 포함한 코팅 액을 다루는 경우, 정체 영역에 적층된 입자가 고형화로 진행될 수 있고 코팅 유동의 변화를 줄 가능성이 있다. Fig. 10에 기본 다이와 converging 형태의 다이에서 비뉴튼성 유체의 출구 속도분포가 비교 되어 있다 $50 \%$ converging은 chamber 양단의 면적이 중간에 비해 $50 \%$ 가 감소하였음을 의미함). Converging을 많이 시킨 경우, 폭방향 으로 속도분포가 더 불균일해지는데 공간이 줄어든 chamber 양단으 로의 유체 흐름이 원활하지 않기 때문이다. 하지만 다이 양단의 공 간을 줄여줌으로써 정체영역(유체속도의 크기가 $10^{-4} \mathrm{~m} / \mathrm{s}$ 이하의 영 역이라고 정의함)이 현저히 줄어들었다.

위에서 언급한 coat-hanger와 converging 형태의 장점을 함께 결 합한 hybrid 형태의 다이로부터 속도의 균일성이 보장된 최적화된

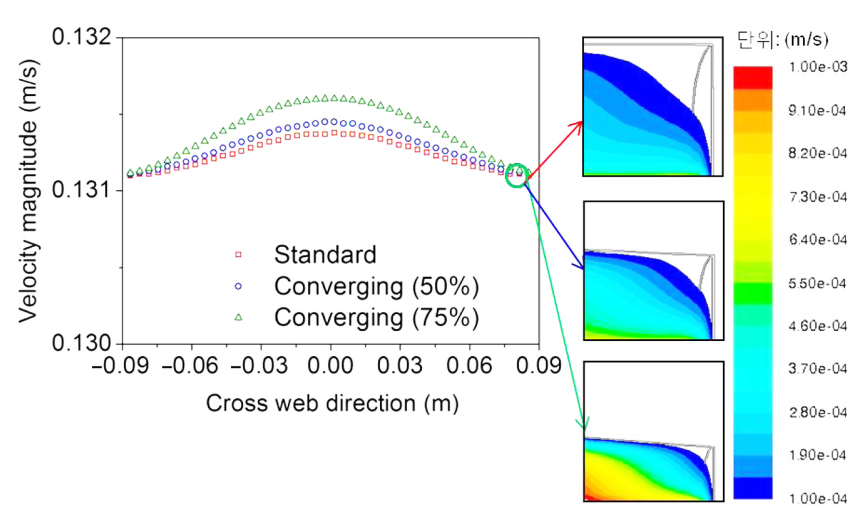

Fig. 10. Effect of converging chamber on velocity distribution at die exit for non-Newtonian liquid.

Korean Chem. Eng. Res., Vol. 49, No. 3, June, 2011 


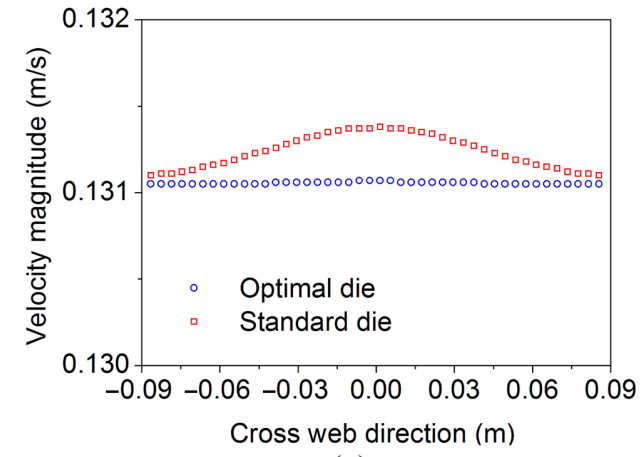

(a)
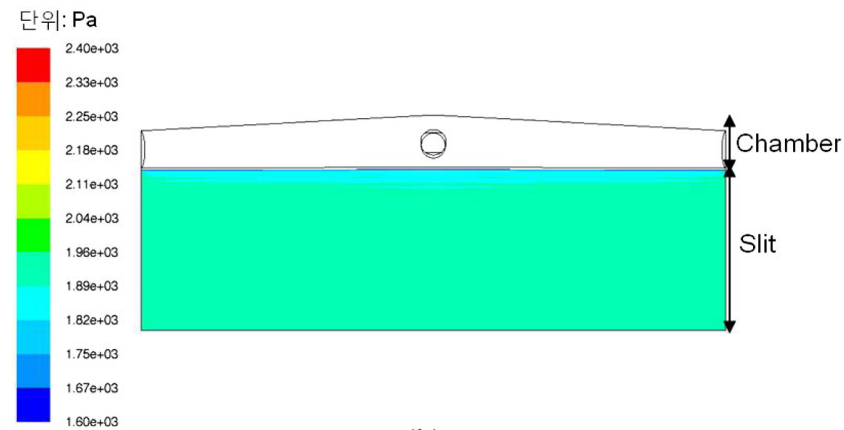

(b)

Fig. 11. (a) Velocity profile at die exit and (b) wall shear-rate distribution in slit regime of non-Newtonian liquid using a hybrid optimal die.

다이를 설계할 수 있다(Fig. 11). 본 연구에서는 다이 출구에서 폭방 향으로의 속도 편차가 $4 \times 10^{-5} \mathrm{~m} / \mathrm{s}$ 이내에 있는 경우 속도분포가 균 일하다고 설정함으로써 비뉴튼성 유체에 대한 최적화 다이 $(50 \%$ converging과 $0.15 \mathrm{~mm}$ coat-hanger 구조)를 도출하였다. Fig. 11에서 다이 출구에서의 폭방향 속도와 slit 내부에서 전단변형률속도가 균 일함을 보여주고 있다. 또한, Fig. 12에서는 유체의 전단담화 정도 $(n)$ 와 converging 비율에 따라 속도 균일성을 위한 coat-hanger 길이 변 화를 도시하였다. Power-law index(n)이 감소할수록 즉, 전담담화 특 성이 커질수록 다이 출구에서의 폭방향 속도를 균일하게 하기 위한 coat-hanger 길이를 크게 해야 하며 또한, converging을 더 부여하는 경우, 양단 영역에서 유량 감소로 인한 속도 저하를 만회하기 위해 coat-hanger 길이가 증가함을 알 수 있다. 다른 다이 구조나 공정조 건에서의 유체물성과 chamber 구조간의 상관관계는 달라지겠으나

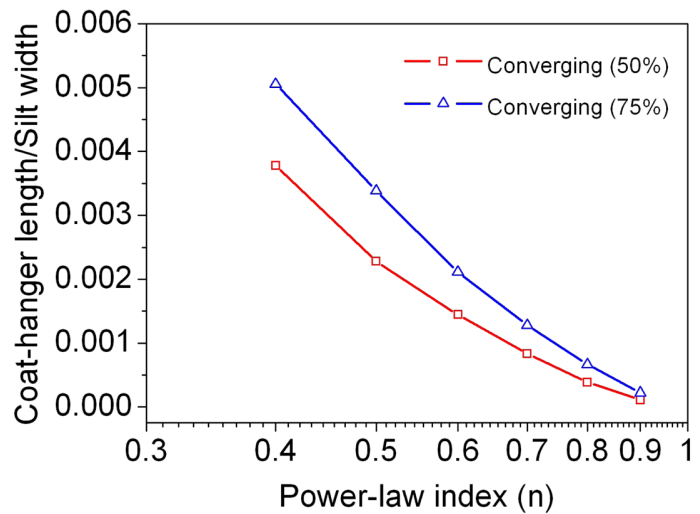

Fig. 12. Relation between coat-hanger length and power-law index(n) for the different converging chambers.
동일한 방법론이 적용된다. 따라서, 본 연구에서 수행한 코팅액의 유 변물성에 따른 다이 내부구조의 변화는 실제 산업공정에서 균일하고 안정된 박막 코팅제품을 생산할 때 유용한 정보를 제공할 수 있다.

\section{4. 결 론}

본 연구에서는 slot 코팅 공정의 핵심요소로 다이 내부 유동을 체 계적으로 관찰함으로써, 전담담화의 유변특성을 갖는 비뉴튼성 용액 의 균일 코팅성을 보장하기 위한 최적 다이를 설계하였다. 다이 출 구에서의 속도 분포를 주요 인자로 선정하여 chamber와 slit 구조에 따른 변화 영향을 분석하여 converging과 coat-hanger 형태가 결합된 hybrid 최적 다이를 제안하였다. 비뉴튼성 유체의 물성 인자 중에서 power-law index $(n)$ 가 최종 코팅 두께 변화에 큰 영향을 주는 것을 파악하였고, 이 변수와 coat-hanger 길이의 상호관계를 규명하였다. 이러한 방법으로 구축된 최적화 다이는 물성이나 운전조건의 미세한 변화에 민감하지 않아 기존 다이보다 민감도 측면에서 큰 장점을 지 니고 있다.

\section{감 사}

본 연구는 청정제조기반 산업원천기술개발사업(지식경제부 과제 번호 10035163)의 지원으로 수행되었습니다.

\section{참고문헌}

1. Ruschak, K. J., "Limiting Flow in a Pre-metered Coating Device," Chem. Eng. Sci., 31, 1057(1976).

2. Higgins, B. G. and Scriven, L. E., "Capillary Pressure and Viscous Pressure Drop Set Bounds on Coating Bead Operability," Chem. Eng. Sci., 35, 673(1980).

3. Sartor, L., Slot Coating: Fluid Mechanics and Die Design. PhD Thesis, University of Minnesota(1990).

4. Gates, I. A., Slot Coating Flows: Feasibility, Quality. PhD Thesis, University of Minnesota(1999).

5. Lee, K. Y., Liu, L. D. and Liu, T. J., "Minimum Wet Thickness in Extrusion Slot Coating," Chem. Eng. Sci., 47, 1703(1992).

6. Carvalho, M. S. and Khesghi, H. S., "Low-flow Limit in Slot Coating: Theory and Experiments,' AIChE J., 46, 1907(2000).

7. Ning, C. Y., Tsai, C. C. and Liu, T. J., "The Effect of Polymer Additives on Extrusion Slot Coating," Chem. Eng. Sci., 51, 3289 (1996).

8. Yang, C. K., Wong, D. S. and Liu, T. J., "The Effects of Polymer Additives on the Operating Windows of Slot Coating,' Polym. Eng. Sci., 44, 1970(2004).

9. Romero, O. J., Suszynski, W. J., Scriven, L. E. and Carvalho, M. S., "Low-flow Limit in Slot Coating of Dilute Solutions of High Molecular Weight Polymer,' J. Non-Newtonian Fluid Mech., 118, 137(2004).

10. Carley, J. F., "Flow of Melts in 'Crosshead'-slit Dies: Criteria for Die Design,' J. Appl. Phys., 9, 1118(1954).

11. Pearson, J. R. A., "Non-Newtonian Flow and Die Design," Trans. J. Plastics Inst., 32, 239(1964).

12. McKelvey, J. M. and Ito, K., "Uniformity of Flow From Sheeting Dies,' Polym. Eng. Sci., 11, 258(1971). 
13. Matsubara, Y., "Geometry Design of a Coat-Hanger Die with Uniform Flow Rate and Residence Time Across the Die Width," Polym. Eng. Sci., 19, 169(1979).

14. Lee, K. Y. and Liu, L. D., "Design and Analysis of a Dual-cavity Coat-hanger Die,' Polym. Eng. Sci., 29, 15(1989).

15. Tadmor, Z., Broyer, E. and Gutfinger, C., "Flow Analysis Network
(FAN) Method for Solving Flow Problems in Polymer Processing,' Polym. Eng. Sci., 14, 660(1974).

16. Wang, Y., "Extrusion of Rubber Compounds and Highly Filled Thermoplastics through Coathanger Dies,' Int. Polym. Proc., 6, 311 (1991).

17. Fluent 6.2 User's Guide, Fluent Inc. 